\title{
Intelligent Bio-Environments: Exploring Fuzzy Logic Approaches to the Honeybee Crisis
}

\author{
M Bassford and B Painter \\ Centre for Computational Intelligence / Institute of Energy and Sustainable Development \\ De Montfort University, Leicester, UK \\ mbassford@dmu.ac.uk
}

\begin{abstract}
This paper presents an overview of how fuzzy logic can be employed to model intelligent bio-environments. It explores how non-invasive monitoring techniques, combined with sensor fusion, can be used to generate a warning signal if a critical event within the natural environment is on the horizon. The honeybee hive is presented as a specific example of an intelligent bio-environment that unfortunately, under certain indicative circumstances, can fail within the natural world. This is known as Colony Collapse Disorder (CCD). The paper describes the design of a fuzzy logic methodology that utilizes input from non-invasive beehive monitoring systems, combining data from dedicated sensors and other disparate sources. An overview is given of two fuzzy logic approaches that are being explored in the context of the beehive; a fuzzy logic system and an Adaptive Neuro-Fuzzy Inference System (ANFIS).
\end{abstract}

Keywords- fuzzy logic, ANFIS, sensor fusion, intelligent environment

\section{INTRODUCTION}

Intelligent environments are physical spaces in which information, communication technologies and sensor systems blend seamlessly into the surroundings. Traditionally this includes man-made environments including physical objects, infrastructures, and the surroundings in which we live, travel, and work. The natural world however never ceases to fascinate mankind, and by blending innovative technologies with sensor fusion, non-invasive monitoring of nests, hives, warrens, burrows etc is now achievable. Thus, there is an increasing drive to monitor intelligent bio-environments, particularly in pursuit of discovering why some natural systems, such as beehives, become unstable under certain conditions. Noninvasive monitoring is essential, but the complexities owing to the unpredictability of nature pose additional challenges in the study of intelligent bio-environments.

Work is in progress to develop a sophisticated remote monitoring system that benefits from sensor fusion. Combining the inputs of several sensors in an environmental monitoring device provides comprehensive data and therefore a greater insight into unusual intelligent bio-environments. The opportunity to employ fuzzy logic for data analysis arises. This paper proposes a methodology for a fuzzy system to flag a 'critical event' in an intelligent bio-environment using a sensor fusion model. A case example is explored: A beehive monitoring system, that fuses sensor data obtained both internally within a hive and externally from a weather station.

\section{InTELLIGENT BIO-ENVIRONMENTS: THE HONEYBEE HiVE CASE STUDY}

Intelligent bio-environments are some of the most challenging spaces to investigate - a large number of variables need to be considered, requiring a vast array of sensors to gather data. In this section, the honeybee hive will be considered in terms of the parameters of a healthy hive and indicators of when a hive becomes unstable. These parameters will be used to outline a sensor fusion model that can be incorporated into the methodology of a fuzzy system (described in section III).

\section{A. The Honeybee Hive}

Beehives are an excellent example of an intelligent bioenvironment that greatly benefits from non-invasive monitoring techniques. The Honeybee (Apis Mellifera) is of significant importance to the human population and agricultural sector across the world due to its exceptional ability to pollinate crops. However, there is an ongoing global puzzle regarding the continuing high losses in bee colonies [1]. These losses have become known as Colony Collapse Disorder (CCD); a phenomenon that occurs when the majority of worker bees in a colony disappear and leave behind a queen, plenty of food and a few nurse bees to care for the remaining immature bees and the queen. High losses in bee colonies eventually lead to the obliteration of the beehive [2]. The UK is suffering one of the worst rates of honeybee colony deaths in Europe. In the cold winter of $2012-13,29 \%$ of colonies in the UK died, with only Belgium suffering a higher rate of losses (34\%) of the 17 countries surveyed. By contrast, only $5 \%$ of colonies in Italy were lost [3].

Although scientists understand what causes the bees to die, they have yet been able to find out what causes diseases to break out [2]. Many causes are currently being considered, such as pesticides, mites, fungi, beekeeping practices (such as the use of antibiotics or long-distance transportation of beehives), malnutrition, poor quality queens, starvation, other pathogens and immunodeficiencies. The current consensus amongst the scientific community is that no single factor is causing CCD, but that several factors in combination may lead to CCD either additively or synergistically. The following sections give an overview of the various parameters that should be considered when monitoring a hive for possible CCD, by first establishing the conditions of a healthy hive. 


\section{B. Beehive Crisis Management - what is a healthy beehive?}

Whilst it is inherently difficult to determine whether a beehive is healthy or not, there are a number of key indicators that a beehive is failing:

1. Temperature within the beehive. Brood nest temperature is of extreme importance to the colony and is controlled with utmost precision [4,5]. Honeybees maintain the temperature of the brood nest between $32^{\circ} \mathrm{C}$ and optimally $35^{\circ} \mathrm{C}$ so that the brood develops normally. It should be noted that variation in the brood temperature could signal a broodless state, which could be due to seasonal influences, non-laying queen, queenlessness, preparations for swarming or the onset of CCD. If we wish to establish a system that only identifies a situation whereby CCD may be imminent, but avoids false alarms (i.e. where temperature deviation is due to other non-fatal scenarios), the temperature of the hive needs to be considered in conjunction with other signs and symptoms, as detailed below.

2. Activity in relation to the weather. One can only understand the measurements inside the beehive correctly if information about the local weather is available. For example, a fall in internal hive temperature might be due to an out-breaking disease within the beehive or due to a cold weather front.

3. Weight of the beehive. The weight supplies crucial information about the development of a beehive. An increase of the hive's weight shows that it is active, meaning it produces brood or honey [6].

4. Beehive occupancy and behaviour. Occupancy monitoring can reveal crucial information related to the number and maturity of bees, as well as colony behaviour in relation to consumption of food. A colony which has collapsed is generally characterized by all of these conditions occurring simultaneously:

- Complete absence of adult bees, with little or no buildup of dead bees in proximity of the hive.

- Presence of capped brood in abandoned colonies: bees normally will not abandon a hive until the capped brood have all hatched.

- Presence of food stores which are not immediately robbed by other bees or hive pests.

- $\quad$ Presence of the queen bee: Queenlessness is not considered CCD.

Precursor symptoms that may arise before the final colony collapse would typically include an insufficient workforce to maintain the brood that is present, a workforce consisting of young adult bees and colony members that are reluctant to consume provided feed. Thus multiple parameters and their complex interrelationships need to be considered when assessing risk of $\mathrm{CCD}$, especially if false alarms are to be avoided.

\section{Beehive Monitoring Systems and Sensor Fusion}

There is great value in using an automated monitoring system to collect information about an intelligent bioenvironment and explore the critical point at which the natural environment starts to fail. An automated system monitors predetermined values/conditions within, for example the beehive, and also it's surrounding, by utilising a variety of sensors. The data can be used in real time to judge the current health status of the bee colony. An additional benefit is that the acquired data from an automated system can be archived and later processed to attempt to draw conclusions from the data. It is important that natural behaviour within a beehive is monitored and therefore the system must be non-invasive.

There have been many research and commercial approaches to developing beehive monitoring systems $[7,8,9]$. The work presented here utilises a prototype computational camera that is capable of capturing advanced visual and environmental data and processing it in real-time, before wirelessly transmitting it to a cloud for further processing if required [10,11]. A number of colony level related parameters can be continuously measured: temperature, air humidity, gas content, sound, vibration of hive, counting of outgoing and incoming bees, video observation and weighing [12]. Various projects have monitored a range of parameters [13], however, the interrelationships are complex and the resulting data sets are large, which makes analysis and interpretation of the data difficult. Given this complexity and associated uncertainty, a fuzzy logic approach may be particularly suitable in order to extract meaningful warning signals from the monitoring data.

\section{FUZZY LOGIC IN INTELLIGENT BIO-ENVIRONMENTS}

Fuzzy logic techniques have been applied to many fields in which uncertainty is present, such as financial forecasting [14], building energy management [15], clinical diagnosis [16] and a variety of medical applications [17]. In this section we explore fuzzy logic as a tool to predict the collapse of a honeybee hive. Two fuzzy logic approaches will be considered; a fuzzy logic system and an Adaptive Neuro-Fuzzy Inference System (ANFIS).

\section{A. Fuzzy Logic Systems}

The topic of fuzzy systems is well documented [18,19]. In this application, the task of the fuzzy logic approach is to monitor all measured parameters and to generate alarms and store recordings of the data. To this end, decisions as to the status of each parameter have to be made, e.g. whether or not the temperature within the hive is considered low, and an assessment of the risk of CCD being on the horizon made based on these decisions. The difficulty is in the classification of the status of the parameters; in a strictly Boolean system, temperature would be classified as either high or not high with some specific value determining the boundary between these two classifications. Fuzzy logic, on the other hand, allows for a means of classification that has more gradual boundaries.

Several parameters for non-invasive hive monitoring can be identified, whereby CCD is considered imminent based on a complex combination of the following criteria: 
1. if the temperature within the hive, $\mathrm{T}$, deviates from the normal operating range of $32^{\circ} \mathrm{C}$ to $35^{\circ} \mathrm{C}$, that local weather variations can not account for;

2. if the weight, W, of the hive does not gradually increase over a period of time;

3. if there is the presence of capped brood;

4. if there is a presence of food stores;

5. if there is a presence of the queen bee;

6. if the occupancy data indicates that:

a. there is an insufficient workforce to maintain the brood that is present;

b. the workforce is made up of young adult bees; or

c. the colony members are reluctant to consume provided feed.

An extended set of variables were established from the above parameters, as defined in Table 1. Note the absence of 'queen bee presence'; a Boolean parameter. Fuzzy sets for use in the algorithm are under construction in on-going work, based on the ranges of values of these variables, as shown in Figure 1.

TABLE I. FUZZY LOGIC ALGORITHM INPUT VARIABLES

\begin{tabular}{|l|l|c|}
\hline Variable & \multicolumn{1}{|c|}{ Description } & Units \\
\hline $\mathrm{T}_{\mathrm{H}}$ & Temperature within hive & ${ }^{\circ} \mathrm{C}$ \\
\hline$\Delta \mathrm{T}_{\mathrm{E}}$ & $\begin{array}{l}\text { External temperature deviation: Percentage } \\
\text { deviation from moving average }\end{array}$ & $\%$ \\
\hline$\Delta \mathrm{W}_{\mathrm{H}}$ & $\begin{array}{l}\text { Hive weight deviation: Percentage deviation } \\
\text { from moving average }\end{array}$ & $\%$ \\
\hline $\mathrm{B}_{\mathrm{C}}$ & Capped brood & binary \\
\hline $\mathrm{F}_{\mathrm{S}}$ & Food store & binary \\
\hline $\mathrm{F}_{\mathrm{C}}$ & Food consumption & binary \\
\hline $\mathrm{W}_{\mathrm{C}}$ & Workforce count & binary \\
\hline $\mathrm{W}_{\mathrm{M}}$ & Workforce maturity & binary \\
\hline $\mathrm{Q}$ & Queen bee & binary \\
\hline
\end{tabular}

Fuzzy systems are based on evaluating the truth of a set of propositions concerning the input variables. Each proposition will have a degree of truth based on the membership value defined by the fuzzy set for the particular value of its input variable. The truth values associated with all of the propositions are then combined to give an output fuzzy set, a process referred to as output composition. The method of composition being explored in the authors' algorithm is the 'fuzzy additive' method, which sums the truth values determined for each proposition across the range of input values, with the maximum resulting value limited to unity. Once this is accomplished, the output fuzzy region must be defuzzified or decomposed to find a single value of output 'truth'. In this application, this is done using the 'centre of gravity' technique and involves finding the centroid of the composed output fuzzy region by calculating the weighted mean of the function over this region $[18,19]$. The resulting output truth value is then used as input to the output fuzzy set which will generate the value of the final output variable based on the description of this set. The set of rules used in the algorithm is given in Table 2.
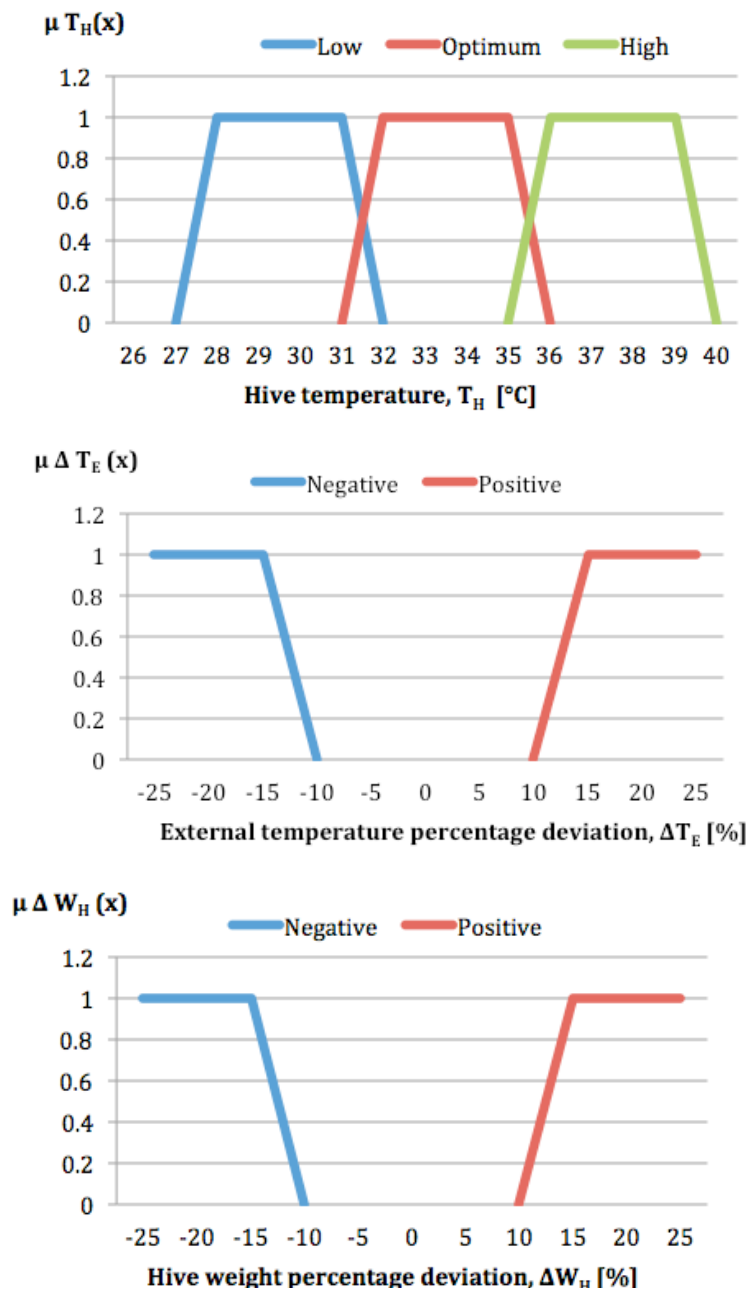

Fig. 1. Fuzzy sets for (top) temperature within the hive, (middle) external temperature and (bottom) hive weight.

TABLE II. FUZZY ALGORITHM Propositions

\begin{tabular}{|c|l|l|}
\hline Rule & & \multicolumn{1}{c|}{ Proposition } \\
\hline Rule 1 & $\begin{array}{l}\text { IF } \\
\text { AND } \\
\text { THEN }\end{array}$ & $\begin{array}{l}\text { temperature within hive } \mathrm{T}_{\mathrm{H}} \text { is LOW } \\
\text { External temperature deviation } \Delta \mathrm{T}_{\mathrm{E}} \text { is SMALL } \\
\text { POTENTIAL CCD }\end{array}$ \\
\hline Rule 2 & $\begin{array}{l}\text { IF } \\
\text { AND } \\
\text { THEN }\end{array}$ & $\begin{array}{l}\text { temperature within hive } \mathrm{T}_{\mathrm{H}} \text { is HIGH } \\
\text { External temperature deviation } \Delta \mathrm{T}_{\mathrm{E}} \text { is SMALL } \\
\text { POTENTIAL CCD }\end{array}$ \\
\hline Rule 3 & $\begin{array}{l}\text { IF } \\
\text { THEN }\end{array}$ & $\begin{array}{l}\text { Hive weight deviation } \Delta \mathrm{W}_{\mathrm{H}} \text { is NEGATIVE } \\
\text { POTENTIAL CCD }\end{array}$ \\
\hline Rule 4 & $\begin{array}{l}\text { IF } \\
\text { THEN }\end{array}$ & $\begin{array}{l}\text { Hive weight deviation } \Delta \mathrm{W}_{\mathrm{H}} \text { is ZERO } \\
\text { POTENTIAL CCD }\end{array}$ \\
\hline Rule 5 & $\begin{array}{l}\text { IF } \\
\text { THEN }\end{array}$ & $\begin{array}{l}\text { capped brood } \mathrm{B}_{\mathrm{C}} \text { is PRESENT } \\
\text { POTENTIAL CCD }\end{array}$ \\
\hline Rule 6 & $\begin{array}{l}\text { IF } \\
\text { THEN }\end{array}$ & $\begin{array}{l}\text { food store } \mathrm{F}_{\mathrm{S}} \text { is } \mathrm{PRESENT} \\
\text { POTENTIAL CCD }\end{array}$ \\
\hline Rule 7 & $\begin{array}{l}\text { IF } \\
\text { THEN }\end{array}$ & $\begin{array}{l}\text { food consumption } \mathrm{F}_{\mathrm{C}} \text { is LOW } \\
\text { POTENTIAL CCD }\end{array}$ \\
\hline Rule 8 & $\begin{array}{l}\text { IF } \\
\text { THEN }\end{array}$ & $\begin{array}{l}\text { workforce count } \mathrm{W}_{\mathrm{C}} \text { is LOW } \\
\text { POTENTIAL CCD }\end{array}$ \\
\hline Rule 9 & $\begin{array}{l}\text { IF } \\
\text { THEN }\end{array}$ & $\begin{array}{l}\text { workforce maturity } \mathrm{W}_{\mathrm{M}} \text { is IMMATURE } \\
\text { POTENTIAL CCD }\end{array}$ \\
\hline
\end{tabular}




\section{ADAPTIVE NEURO-FUZZY INFERENCE SYSTEMS (ANFIS)}

An alternative approach to developing a fuzzy system using a set of rules is to find out more about how sensor values diverge, by generating data of both healthy and infected beehives over a period of time. A beehive monitoring system would serve the purpose of generating the necessary data if replicated with a series of comparable hives. This approach would employ Adaptive Neuro-Fuzzy Inference Systems (ANFIS) [20], which utilizes a learning algorithm to define input-output relationships through hybrid learning to determine the optimal parameters of membership functions.

Using this approach, an intelligent beehive model can be designed to make a reliable crisis determination estimate from internal and external beehive variables, as described in Table 1. An ANFIS algorithm can be used to investigate the relationship between these variables, using a fuzzy system, as described in the previous fuzzy logic approach. Data leaving a pre-processing stage would enter into a 'fusion centre' in different streams: hive events (imaging data, vibration measurements), hive climatic data (humidity, illuminance, temperature) and external activity (local weather). Hive occupancy count estimated by ANFIS could then be fed back into the fusion centre to improve the accuracy of subsequent honeybee occupancy and behaviour estimation.

\section{Discussion AND CONCLUSIONS}

Blending sensor fusion with fuzzy logic provides an exciting opportunity to explore comprehensive yet complex sets of data with which to study and model intelligent bioenvironments. This paper shows 'work in progress' in the production of a methodology for a fuzzy system to flag instability or a 'critical event' in an intelligent bio-environment using a sensor fusion model. The case example given here, a beehive monitoring system, that fuses sensor data obtained both internally within a hive and externally from a weather station, has highlighted the need for careful consideration of a number of key indicators. The interplay is complex and two alternative approaches to handling the data are being considered. We already have sufficient 'expert information' with which to define sets of fuzzy rules. Thus, the next phase of work includes a comprehensive development of the algorithm using the MATLAB fuzzy toolbox. With initial data and potential on-going 'real' data that can be obtained from real beehives however, it would be possible to include longterm sensor fusion data and explore the ANFIS model.

Much work remains; the practicalities of non-invasive monitoring in itself prove challenging. A review of the effects of electromagnetic (EMF) fields on wildlife, humans and plants [21] reported negative effects on honeybees from exposure to EMF radiation. It is therefore essential that pollutants and interference with natural conditions, due to monitoring activities, are sensibly recognized and eliminated otherwise the data gathered would misrepresent the true behaviour of the hive.

\section{ACKNOWLEDGMENT}

Thanks to Professor Bob John for fuzzy logic advice.

\section{REFERENCES}

[1] T. Stankus, "A review and bibliography of the literature of honey bee Colony Collapse Disorder: a poorly understood epidemic that clearly threatens the successful pollination of billions of dollars of crops in America," Journal of Agricultural \& Food Information, 9.2 (2008), pp.115-143.

[2] D. Van Engelsdorp et al., "Colony collapse disorder: a descriptive study," PLoS One, 4(8):e6481, 2009.

[3] M. Laurent, P. Hendrikx, M. Ribiere-Chabert and M. Chauzat, A panEuropean epidemiological study on the honeybee colony losses 20122014, http://ec.europa.eu/food/animals/live animals/bees/docs/beereport_2012_2014_en.pdf (accessed March 2016).

[4] M.L. Winston, The Biology of the Honey Bee, Harvard University Press, Cambridge Massachusetts, 1987.

[5] J. Tautz, The Buzz about Bees, Springer-Verlag, Berlin Heidelberg, 2008

[6] Barkston Ash BeeKeepers Association, http://www.bbka.org.uk/local/barkston-ash/johnsponderings/heavyman.shtml (accessed March 2016).

[7] J. Odoux, P. Aupinel, S. Gateff, F. Requier, M. Henry and V. Bretagnolle, "ECOBEE: a tool for long-term honey bee colony monitoring at the landscape scale in West European intensive agroecosystems," J. of Api. Res, vol. 53, no. 1, pp. 57-66, 2014.

[8] R. D. Phillips, J. Blum, M. A. Brown, and S. L. Baurley, "Testing a grassroots citizen science venture using open design, the bee lab project," CHI'14 Extended Abstracts on Human Factors in Computing Systems, ACM, 2014, pp. 1951-1956.

[9] Remote Bee Hive Monitoring System, http://www.arnia.co.uk/ (accessed March 2016).

[10] M. Bassford, and B. Painter, "Development of an Intelligent Fisheye Camera," Proceedings of IEEE International Conference on Intelligent Environments (IE’15), 15-17 July 2015, Prague, Czech Republic.

[11] B. Painter, M. Bassford, and M. Downey, "Validation of a novel luminance based sensor system for visual environment monitoring and control," Proceedings of IET Future Intelligent Cities Conference, 4-5 December 2014, London, UK.

[12] A. Zacepins, and K. Toms, "Application of temperature measurements for the bee colony monitoring: a review," Proc. of the 12th International Scientific Conference Engineering for Rural Development, 2013.

[13] F.E. Murphy, et al. "Big brother for bees (3B) - Energy neutral platform for remote monitoring of beehive imagery and sound," in Advances in Sensors and Interfaces (IWASI), 2015 6th IEEE International Workshop on, vol., no., pp.106-111.

[14] J. Garibaldi, Fuzzy expert systems, Do Smart Adaptive Systems Exist? Springer Berlin Heidelberg, 2005, pp. 105-132.

[15] A. I. Dounis, "Artificial intelligence for energy conversation in buildings", Advances in Building Energy Research, vol. 4, no. 1, pp. 267-299, 2010.

[16] R. John and P.R. Innocent, "Modeling uncertainty in clinical diagnosis using fuzzy logic,” IEEE Trans Syst Man Cybern B Cybern. 35(6), pp. 1340-50, 2005.

[17] M.J. Burke and R. Downes, “A fuzzy logic based apnoea monitor for SIDS risk infants", Journal of medical engineering \& technology: United Trade Press; 2006, 30:397.

[18] E. Cox, The Fuzzy Systems Handbook: A practitioner's guide to building, using and maintaining fuzzy systems, New York, NY: Academic Press, 1994.

[19] G.J. Klir and B. Yuan, "Fuzzy Sets and Fuzzy Logic - Theory and Applications," Upper Saddle River, NJ: Prentice Hall, 1995.

[20] J.S.R. Jang, "ANFIS: adaptive-network-based fuzzy inference system," Systems, Man and Cybernetics, IEEE Transactions on 23.3 (1993): pp. 665-685.

[21] S. Sivani and D. Sudarsanam, "Impacts of radio-frequency electromagnetic field (RF-EMF) from cell phone towers and wireless devices on biosystem and ecosystem-a review," Biology and Medicine 4.4 (2012): 202. 